\title{
A PEDAGOGIA DE HERBART REINTERPRETADA COM O PROF. DR. DIETRICH BENNER*
}

\author{
OdAir NeItzel
}

\section{Introdução}

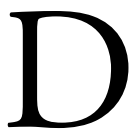

ietrich Benner nasceu no dia $1^{\circ}$ de março de 1941 , na cidade de Neuwied, na Alemanha. É professor aposentado de Ciências da Educação da Universidade Humboldt de Berlim. Em 1970, habilitou-se na Faculdade de Letras da Universidade de Bonn para a área de Ciências da Educação. Nos anos seguintes, ocupou a cadeira de Eugen Fink na Universidade de Freiburg (1971 e 1972). Em 1973, foi nomeado professor titular de Ciências da Educação na Universidade de Münster (1973 a 1991). Nos anos de 1976 e 1977, recebeu novas chamadas para as universidades de Klagenfurt e Zurique. Em 1991, aceitou o cargo de professor de Ciências da Educação Geral na Universidade Humboldt de Berlim, onde trabalhou até sua aposentadoria, em 2009. Em 2008, foi nomeado professor honorário de Ciências da Educação na Universidade Cardeal Stefan Wyszyński (UKSW), em Varsóvia, onde estruturou os estudos de Fundamentos em Ciência da Educação. Há muitos anos é professor visitante nas universidades de Freiburg, Zurique, Basileia, Odense e Viena. De 1981 a 2003, Dietrich Benner foi coeditor da revista de pedagogia Zeitschrift für Pädagogik. De 1989 a 1994, foi presidente da Sociedade Alemã de Ciências da Educação (Deutsche Gesellschaft für Erziehungswissenschaft — DGfE). Em 2004, ele recebeu o título de professor emérito na East China Normal University (ECNU), de Xangai. Em 2009, recebeu o título de douctor honoris causa pela Universidade de Aarhus, na Dinamarca, e, em 2011, o títuloDoutor doctor honoris causa pela Universidade Åbo Akademi, da Finlândia. Em 2014, foi condecorado com a medalha da Comissão Nacional

\footnotetext{
*A presente entrevista, realizada com o Professor Dr. Dietrich Benner, gira em torno do tema da Pedagogia Geral de Johann Friedrich Herbart. Além de oferecer contribuiçóes para a investigação educacional, ela tem como objetivo sinalizar para a releitura do filósofo e pedagogo Herbart, visando corrigir um conjunto de equívocos de interpretação, leitura e compreensão. A entrevista soma-se aos esforços em mostrar a importância de seu pensamento para a reflexão sobre a ação pedagógica no cenário da educação contemporânea. Ela foi feita com base em questóes semiestruturadas presencialmente, gravadas em áudio, transcritas e traduzidas pelo entrevistador.

${ }^{1}$ Universidade Federal da Fronteira Sul - Chapecó (SC), Brasil. E-mail: odair.neitzel@uffs.edu.br DOI: 10.1590/ES0101-73302019207420
} 
de Educação pelos trabalhos desenvolvidos no sistema de educação da Polônia. Os seus principais temas de pesquisa são: pedagogia geral e sistemática; teoria da educação: didática geral e teoria da aprendizagem; teoria da escola; história da teoria da ciência educacional; história da pedagogia da reforma; e teoria da formação e pesquisa educacional.

\section{Entrevista}

Odair Neitzel: Prof. Dr. Dietrich Benner, o senhor poderia partilhar alguns aspectos da sua biografia? Por que se interessou por pedagogia e filosofia?

Dietrich Benner: Depois da graduação em Filosofia, Pedagogia, História Antiga e Germanística, fiz meu doutorado em Filosofia, em 1964 e 1965. A tese foi sobre Hegel e Marx, com concentração em Filosofia. Então, foi-me ofertado pelo meu supervisor austríaco de doutorado, o filósofo vienense Erich Heintel, um cargo de assistente no Departamento de Filosofia da Universidade de Viena, no entanto o Ministério da Ciência austríaco recusou-me o cargo como jovem cientista alemão na época — dez anos após a conclusão do Tratado de Estado, de 1955 (Österreichischer Staatsvertrag). Felizmente, pouco tempo depois, Josef Derbolav, professor austríaco de Filosofia e Educação na Rheinische Friedrich-Wilhelm-Universität, em Bonn, ofereceu-me a oportunidade de assumir um cargo de professor na área pedagógica e logo fui elevado ao nível de professor-assistente. Eu vim da filosofia para a educação não de modo solitário, mas com Wolfdietrich Schmied-kowarzik, que, um ano antes, depois de seu doutoramento com Erich Heintel, em Bonn, assumira um cargo de assistente. Naquela universidade, conheci vários outros colegas austríacos que haviam estudado com Heintel, como Franz Fischer, Herbert Hornstein e Herbert Zdarzil.

A década de 1960 foi um período pobre em modelos tratando-se da relação entre filosofia e pedagogia. O caminho da filosofia para a pedagogia que eu e Wolfdietrich Schmied-Kowarzik escolhemos era longo. Os primeiros clássicos que Wolfdietrich Schmied-Kowarzik e eu lemos e discutimos juntos foram Fichte e os fichteanos, que, por volta de 1800, trabalharam em uma base filosófica da ciência educacional. Depois, vieram ensaios intensivos e a ocupação com Rousseau, Herbart, os neokantianos, aqui especialmente Richard Hönigswald, e mais tarde Alfred Petzel e sua escola, de maneira particular Marion Heitger, Wolfgang Fischer e Jörg Rohloff. Ao ocuparmo-nos com essas e outras posiçōes, desenvolvemos o que assumiu a expressão literária de Prolegomena zur Grundlegung der Pädagogik (em português, prolegômenos para a fundamentação da pedagogia) (Prolegomena $z u$ Grundlegung der Pädagogik) I e II (1967; 1969). Assim, esboçamos, em coautoria, uma ordem de pedagogias filosóficas que cobriam desde os ensinamentos de educação pragmática de Rousseau e Schleiermacher, passando por Herbert, e uma filosofia da formação fenomenológica até os fundamentos teóricos básicos 
da filosofia da educação, como, em 1800, tinham sido desenvolvidos no círculo de pensamentos em torno de Fichte e o neokantismo do começo do século XX, especialmente Richard Hönigswald.

Já a partir do fim de 1960, no espaço acadêmico da pedagogia e da ciência da educação, partilhamos do esboço de um programa crítico das ciências sociais de Jürgen Habermas, da crença em seu paradigma como caminho para continuar o desenvolvimento da pedagogia e da ciência da educação. Nesse momento, eu e Schmied-Kowarzik ocupamo-nos em delinear sistematicamente os limites do programa. E buscamos, diante das dúvidas, reconhecer nos processos educacionais sua afinidade com as situações presentes e das novas gerações, em seus contextos educacionais e forças formativas, sustentadas em processos formativos ante as exigências e relaçóes comunicativas entre pessoas e o mundo, operando com a categoria da emancipação como caminho de libertaçáo ou mesmo da abolição da dominação supérflua.

Com a conclusão das habilitações, os nossos caminhos, meu e de Schmied-Kowarzik, foram separados, mas isso nunca nos impediu de continuar a enfrentar os problemas que tínhamos quando trabalhávamos juntos. Desenvolvi a minha própria Pedagogia Geral (2012). Com base em um projeto financiado pela Sociedade Alemã de Desenvolvimento de Projetos, sistematizei a Theorie und Geschichte der Reformpädagogik (Teoria e História da Educação Reformada, em quatro volumes. A obra trata das ideias de experiências pedagógicas desenvolvidas nos Hauptströmungen der Erziehungswissenschaft (2001) e na minha Pedagogia Geral, interpretadas em ordem sistemática, dos princípios pedagógicos, da teoria da ação, das formas de ação sobre a teoria pedagógica e dos problemas da história do pensamento pedagógico da pedagogia reformada e sua atuação na Alemanha.

Atualmente, ocupo-me com o projeto sobre competência religiosa e ética, o qual também está sendo recebido na Dinamarca, sob o título de Competência Religiosa como Parte da Educação Pública. O projeto considera sempre a existência de uma base teórica da educação religiosa e a pesquisa empírica. Com esse projeto, desenvolvo, com a mesma estrutura, um projeto sob o título de Competência Ética e Moral como Parte da Educaçáo Pública, que possui uma base teórica, a consideração do processo de educação moral e democrática e a pesquisa empírica. Expandi o projeto ético para a cooperaçáo internacional no Leste Europeu, na Dinamarca e na Escócia.

Odair Neitzel: No fim dos anos 1960, o senhor, juntamente com o Prof. Dr. Schmied-Kowarzik, conduziu um projeto de leitura dos clássicos da pedagogia intitulado Prolegômenos para a Fundamentação da Pedagogia (1967). Esse trabalho resultou na publicação de dois volumes e de um terceiro inacabado. O primeiro volume contém uma análise do sistema pedagógico de Herbart tendo como referência a filosofia prática geral. O que poderia nos dizer sobre o projeto? Como o senhor o vê hoje retrospectivamente? 
Dietrich Benner: Eu possuo atrás de mim um longo caminho da filosofia para a pedagogia. Ainda sou orientado filosoficamente, mas eu também pesquiso empiricamente. Sim, os filósofos da educação e da formação que somente se enxergam como filósofos e quase não encontram o caminho para a pedagogia, que sempre somente importam, se esquecem, no meu ponto de vista, de ingressar na tradição pedagógica. Trabalhamos com vários autores contemporâneos, transferimos suas ideias para as disciplinas, despedimos a subjetividade moderna e defendemos que liberdade e autonomia são fantasmas etc. Não percebemos que formas de uma pedagogia subjetiva pura e uma autonomia pedagógica absoluta nunca existiram. Nunca! Entáo, em Herbart, se o conhecemos, não as encontramos. Herbart tornou central a liberdade de escolha, mas não reconhece uma liberdade transcendental. Também mantinha certa distância da liberdade interior em relação às motivaçóes individuais. Então, recebemos hoje muitos autores e desconhecemos a própria tradição. E essas importaçóes, permanentemente, não alcançam e são insuficientes para a pedagogia.

Em uma das minhas recentes publicaçóes em homenagem a Albert Schaefer, escrevo sobre poder e reconhecimento no contexto educacional. Fiz uma problematização da recepção de Foucault e da teoria do reconhecimento. É preciso que se questione: qual estrutura de poder tem o governo das crianças? Que estrutura de poder existe no ensino? Que estruturas de poder existem na orientação da disciplina formativa? Isso seria, a meu ver, uma pesquisa das relaçóes de poder pedagógico! Pode-se trazer ao tema muita coisa de Herbart, mas, se não o recepcionamos mais, e não mais distinguimos governo, ensino e disciplina como três formas de ação pedagógica, somente discutindo sobre o poder nos processos educativos, então nós passamos por cima da tradição de tal forma que ela não se torna mais relevante para a práxis pedagógica. É um filosofar sobre a educação e formação com pouca crítica e orientação para a prática concreta.

Esse era o programa do meu projeto e de Schmied-Kowarzik na época. Queríamos sair da filosofia em direção à pedagogia. Denominamos esse projeto de Prolegômenos para a Fundamentação da Pedagogia (1967; 1969). Pretendíamos publicar três volumes. O de Schleiermacher, com sua teoria, falhou. Tivemos êxito com os outros dois volumes, com a fenomenologia da educaçáo de Herbart no centro do primeiro e com a filosofia educacional de Hönigsbach no segundo. Mas abandonei esse sistema depois do projeto Prolegômenos e ocupei-me com a distinção pedagógica interna entre teoria educacional, teoria da formação e teoria das instituições pedagógicas. Esta tríade ensino, fenomenologia e filosofia da educação é uma ordem filosófica interna. Hoje, diria teoria da ação pedagógica em vez de teoria da educação, da formação e da instituição pedagógica. E, então, pedagogia profissional para a profissão e, em seguida, pesquisa pedagógica. Eu não representaria essa tríade por educador, filosofia e fenomenologia. A tríade professor verteu-se em teoria educacional; a fenomenologia tornou-se teoria da formação; a filosofia da educação adentrou nas teorias da educação e formação. E isso se somou à nova 
teoria da escola. Herbart tinha uma teoria da escola. Ele já a conhecia. Hegel tinha uma teoria escolar maravilhosa. Os clássicos, em sua maioria, tiveram uma.

Isso então se deslocou um pouco. Se você olhar para os Hauptströmungen der Erziehungswissenschaft (2001) — que está sendo traduzido para o chinês —, temos uma teoria da educação, a teoria da formação e a teoria da pedagogia. E a teoria da instituição pedagógica contém, já em si, família, escola e instituição da transição para uma profissão, cuja instituição intermediária é o jardim de infância. Assim se desenvolveu isso.

Odair Neitzel: Publicaçóes recentes sobre Herbart apontam para um conjunto de mal-entendidos históricos na leitura e pesquisa da obra do pensador, como o senhor sinalizou na introdução do livro Die Pädagogik Herbarts: Eine problemgeschichtliche Einführung in die Systematik neuzeitlicher Pädagogik (1993). Poderia nos contar algo sobre a recepção de Herbart e sua teoria no passado e como ela se apresenta na atualidade? $\mathrm{O}$ que se deve observar caso alguém se interesse por Herbart?

Dietrich Benner: No Instituto Bonn, onde eu e Schmied-Kowarzik kowarzikcomeçamos como assistentes, havia Herbert Hornstein, que escreveu um livro sobre Herbart e Kant. Ele tomava Kant como o verdadeiro professor de educação e defensor da liberdade, enquanto descrevia Herbart como um pedagogo autoritário do governo das crianças. Ele ainda interpretou Herbart conforme a tradição do Estado prussiano. Nós éramos amigos de Hornstein e, quando terminamos o Prolegômenos I, que tinha como núcleo Herbart, demos a ele uma cópia para ler. Depois de lê-la, ele disse: "Eu interpretei mal Herbart! Vocês têm razão!". Isso foi uma espécie de primeiro controle sobre o nosso projeto. Hoje, diria retrospectivamente: Herbart tornou-se útil nos estados pré-democráticos. Na Rússia, na América do Sul, no Japão, na China e na Alemanha. E essa recepção pré-republicana de Herbart levou os herbartianos a um reducionismo da problemática.

Nos últimos 20 anos, tenho apoiado jovens pesquisadores de Herbart da Polônia, Hungria, Japão e China - para citar alguns contatos mais importantes - em seus escritos de qualificação de doutorado e habilitaçóes. $O$ fato é que na Polônia, Ucrânia, Hungria, em todos os lugares, surgiu uma nova recepção de Herbart. $\mathrm{Na}$ China, há uma nova edição de Herbart, em que foi necessário compilar os textos novamente, pois lá também foram traduzidos incorretamente. Encontramos novas leituras no Japão, na Hungria, na Romênia, no Brasil, e é prazeroso saber disso. $\mathrm{Na}$ Alemanha, há novas publicaçôes. O primeiro foi Bernhart Schwenk (1963) com Das Herbartverständnis der Herbartianer ( $O$ entendimento de Herbart dos herbartianos). Depois dos herbartianos, penso, viemos Schmied-Kowarzik e eu. Klaus Prange (2013) apresentou interpretaçóes maravilhosas. Elmar Anhalt (1999) acrescentou coisas importantes. Então, há uma geração na Alemanha, ainda viva, de intérpretes de Herbart que talvez tenham lido Herbart de modo mais exigente em seus próprios textos. 
A minha mais recente descoberta, após 20 anos de apreciação da Filosofia Prática Geral de Herbart, ocorreu quando li Michael Walzer (2003). Esse filósofo social americano escreveu um livro sobre as esferas da justiça. No meu livro Formação, Moralidade, Democracia (2015), encontra-se uma interpretação de Herbart que tem correspondência na distinção de Walzer entre universalismo, uma lei abrangente que tudo abarca, e universalismo cíclico (universalismos de Wiederholung). Walzer não conhece Herbart, mas ele distingue as esferas da justiça como Herbart, que distinguiu a esfera da justiça nos sistemas trabalhista, remuneratório, jurídico, cultural e administrativo, que abrange hoje tudo o que discutimos como esfera pública. Isso é o que Herbart chamou de "a alma da sociedade" (seele der gesellschaft), e Dewey (1979) chamou de "democracia" (demokratie). Entre o conceito de democracia de Dewey e o conceito de sociedade animada de Herbart, existem grandes afinidades. E, com a ajuda de Walzer, agora posso mostrar que Herbart é muito atual. Para Herbart, o sistema jurídico deve considerar a igualdade diante da lei; no sistema salarial, devem-se considerar diferentes recompensas e puniçóes de acordo com o contexto; no sistema cultural, é central a livre interação que Dewey chama de democracia; no sistema administrativo, diz Herbart, não interessa em absoluto a igualdade. Os necessitados recebem a maior ajuda. Não há igualdade diante do conflito. E quem se destaca no desempenho não receberá distribuição igual. Daremos um Stradivarius a um jovem músico, mas não para um iniciante. Da mesma forma, vamos proporcionar moradia para um desabrigado, porém não para um rico. Portanto, o sistema social tem diferentes critérios de justiça. Isso é o que pensa Walzer, isso é Herbart. Tentei repetidas vezes trazer para a conversa a Filosofia Prática Geral (Allgemeiner Praktische Philosophie) de Herbart (1887a, p. 329-458). Não tive sucesso. Mas agora, por meio das semelhanças de Dewey, Walzer e Herbart, há também uma nova recepção de Herbart em andamento na área de filosofia política e social.

Para o projeto Educação e Competência Ético-moral, desenvolvemos uma abordagem de pesquisa empírica que possui diversas etapas de construção. Deve-se levar em consideração um conjunto de conceitos teóricos. Liberdade interior, perfectibilidade, bem-estar, bondade, equidade, simplesmente denominadas por Herbart de ideias orientadoras (Ideenlehre), associadas às esferas da justiça social, de acordo com pressupostos éticos, aporéticos, periagógicos (periagogisch), teleológicos platônicos, categóricos aristotélicos, críticos e categóricos kantianos.

Aqui Herbart ingressa agora na pesquisa, inclusive sobre competências. Agir é o princípio do caráter, afirmou Herbart. $\mathrm{O}$ caráter não surge do ensino. $\mathrm{O}$ ensino leva ao círculo do pensamento. $\mathrm{O}$ caráter surge na atuação do educando. $\mathrm{E}$ a ação desenvolve a competência ética. ,Aqui, distinguimos a competência em três subcompetências:

- $\quad$ conhecimento básico, mediado pelo ensino;

- $\quad$ capacidade de juízo, o objetivo formativo do ensino;

- $\quad$ orientação, que é a capacidade de participar com o juízo. 
Entendemos essas três competências na ética:

- conhecimentos fundamentais éticos e morais;

- competência de julgamento ético e moral;

- $\quad$ capacidade de propor-se com os outros para agir moralmente.

Isso é a disciplina e a terceira forma de ação pedagógica em Herbart. O aluno atua, e o educador aconselha a açáo.

Com isso, existem novas pesquisas em relação ao tato pedagógico. Como ele surge? Como ele se desenvolve? Como se distingue o tato pedagógico no Japão do tato pedagógico em outros lugares? Busquei dar, nesse sentido, mais um passo no desenvolvimento dessa pesquisa. Isso toca as seguintes questôes: Onde se localiza o tato pedagógico na ação pedagógica do governo das crianças? Em que consiste o tato pedagógico na ação pedagógica do ensino? Em que consiste o tato pedagógico na ação pedagógica do aconselhamento? Herbart não se ocupou disso, embora o sugerisse. $\mathrm{Na}$ palestra sobre o tato pedagógico de 1802 (HERBART, 1887b, p. 279-290), na concepção da Pedagogia Geral de 1806 (HERBART, 1887c, p. 1-139), no período de atividades em Königsberg, ele não fez isso. Mas nós podemos fazê-lo hoje. Podemos pesquisar o tato pedagógico em sua constituição por intermédio da teoria, da formação de professores, na fase de prática, como tato educativo do governo, do ensino e do assessoramento. Em um pequeno ensaio com Brüggen - Die Bildung der pädagogischen Urteils und Handlungskompetenz als Aufgabe pädagogisches Unterricht in öffentliche Schulsystem -, ocupamo-nos com a conexão entre Herbart e a teoria do tato pedagógico e a pesquisa das competências. Eu insiro as novas abordagens e pesquisas do tato pedagógico na pesquisa sobre as competências.

Odair Neitzel: Na minha tese de doutorado, com o tema $A$ pedagogia como autogoverno em Herbart (NEITZEL, 2018), tenho como pano de fundo, especialmente, a filosofia dos séculos. I e II, com a qual Foucault se ocupa em sua A Hermenêutica do Sujeito (2010), para interpretar a pedagogia de Herbart. Em recente publicação, o senhor discute a afirmação de Sêneca "non vitae sed scholae discimus" (apud BENNER, 2011, p. 9). Qual é a influência de Sêneca em Herbart?

Dietrich Benner: Primeiramente, gostaria de estabelecer uma conexão sistemática entre a teoria do tato pedagógico de Herbart em relação à Pedagogia Geral è̀ pesquisa sobre o tato pedagógico de hoje. $\mathrm{O}$ tato pedagógico do governo da criança, diz Herbart, apenas busca evitar uma ação. O fim do tato no governo é evitar danos. Se quiséssemos pesquisar isso agora, então necessitaríamos dizer que o tato pedagógico do governo das crianças, dos pedagogos profissionais, cuida dos educandos de tal modo que, ao final do processo de formaçáo e em meio a ele, sempre eles podem novamente autogovernar-se. Ou seja, não necessitaríamos mais 
de um pedagogo que governa, porém que o tato pedagógico do governo visasse ao autogoverno do educando. $\mathrm{O}$ tato pedagógico no ensino objetiva que o educando possa ensinar a si mesmo sem um professor. E o tato pedagógico do assessoramento, na terceira dimensão, disciplina formativa, objetiva que o educando possa aconselhar a si mesmo com os outros.

Assim, temos três tatos pedagógicos em movimento: do governo dos outros para o governo de si mesmo, do ensino pelo outro para o auto-ensino e do aconselhamento externo para o auto-aconselhamento. Eu compreendo isso como uma teoria do reconhecimento, sustentada em pesquisas sobre competências, como desenvolvimento continuado da pedagogia herbartiana, que reúne o que Herbart nunca reuniu: a teoria do tato pedagógico, a Pedagogia Geral e as pesquisas dos seminários didáticos pedagógicos em Königsberg. As pistas foram dadas por Herbart.

Agora, a síntese do que foi dito: eu escolhi Sêneca e Herbart muitas vezes em palestras sobre a teoria das instituiçôes pedagógicas. O termo grego scholé significa ócio $(\mathrm{Mu} \beta e)$. Aristóteles usa-o para designar como ocupação dos cidadãos livres e libertos do trabalho. Este é um par de opostos: scholé ou ócio e trabalho. Os escravos trabalham e não se ocupam no ócio e também não têm direitos. Mas isso é mais do que apenas um fenômeno de dominação. Aristóteles diz que certas atividades só podem ser feitas em meio ao ócio. Nelas se incluem política, amizade e ciência.

Eu mesmo distingui na práxis a oportunidade para o ócio. Eu considero, assim como já fizera Karl Marx, o trabalho como práxis e também a ética, a política, a religião e a arte. São modos diversos de práxis. Essencialmente, o ócio $(\mathrm{Mu} \beta$ e) também é um horizonte do trabalho. Logo, o trabalhador que continua sua formação deve ter um momento de aprendizagem e ócio no trabalho. Um trabalho que é definido apenas de modo capitalista não é mais uma práxis. E essa é a crítica marxista. Que o trabalho seja retirado da perspectiva de estranhamento capitalista e realocado no horizonte de um trabalho formativo.

Havia uma compreensão totalmente diferente do trabalho na Grécia Antiga. O trabalho era o oposto de formação. Aristóteles diz que a formação e o ócio estão relacionados. Eu diria que, no espaço do trabalho, deve haver espaços de ócio. Caso contrário, o trabalho é ocupação alienante. É aí que entra o termo latino scholé. Scholé é a apresentação do ensino. No termo escola, ambos os conceitos são reunidos. A escola é o lugar da reflexão, do lazer; a apresentação do ensino, entretanto, desempenha papel importante e, por assim dizer, é a história do problema mais antigo. Grandiosa em Aristóteles é a afirmação de que, no fim da aprendizagem, é preciso ser capaz de sustentar e transmitir aos outros o que se aprendeu.

Portanto, certa competência didática deve surgir do percurso formativo. Quem aprendeu algo corretamente pode ensinar algo sobre isso aos outros. Aprender náo é algo de que me aproprio para mim, mas eu desenvolvo como uma 
competência de ensino. Ensino de tal modo que possa ensinar o que aprendera ao outro. Não profissionalmente, mas na conversa e no discurso. Isso exige um momento de ócio em todos os espaços. Mesmo na escola deve haver o espaço para o ócio. É por isso que Herbart diz que, se for ensinar, primeiramente torne isso agradável. Na Pedagogia Geral está escrito que se deve tornar agradável estar com os alunos. É preciso surgir um espaço de ócio, em que se alargam a experiência e a convivência, e não simplesmente se experimenta e se manipula. Para Herbart, se tiver sucesso, a escola é um espaço de ócio onde a experiência e a convivência podem ser alargadas esteticamente.

Esse espaço de ócio $(\mathrm{Mu} \beta e)$, Sêneca cultivou intensamente. Em conversas com seu pupilo, há a afirmação de que a vida se tornara muito comercial, mas que não aprendemos para o negócio, para a agitação. Aprendemos no ócio para o ócio. Essa norma "non vitae sed scholae discimus" facilmente leva a equívocos de interpretação. De modo algum, Sêneca entende que seja para o ócio e não para a vida, mas aprendemos para uma vida em que há ócio. Ele não concebia uma vida dual. Os estoicos queriam uma vida em que o lazer fizesse parte dela. Toda duplicidade deveria ser evitada para que fosse possível conceber essa reivindicação.

No século XVII, temos então o movimento pedagógico da Aufklärung, afirmando que aprendemos para a vida. Isso também está correto! Já em Sêneca, numa vida em que há lugar para o ócio, aprendemos para a vida. Agora, afirmamos que aprendemos para a vida. Nós não aprendemos tão somente como formação intelectual. Esse também não foi o caso com Sêneca. Nós aprendemos para conduzir a vida significativamente. E Herbart sabia disso. Ele fez uma inversão da expressão. Desejamos aprender no ócio de tal modo que possa ser significativo para a vida. Ele rejeitou a dualidade do ócio e da vida. E eu acho que nisso compreendeu Sêneca muito bem. E essas interpretaçóes baratas - que os gregos se organizam em uma sociedade escravocrata e que aprendiam meramente para $o$ ócio e que na modernidade se aprende para a vida — são simplórias e inviáveis.

Eu ainda vejo o efeito tardio da defesa desse pensamento em Hannah Arendt (2013) no texto "A Crise da Educação". Arendt defende um horizonte de ócio e diz que, na escola, não se aprende como num ofício, mas na escola há o pensar, uma reflexividade, um distanciamento da agitação do mundo. É proibido que os professores sejam políticos do Estado. A escola não pode ser definida politicamente, nem os estadistas querer construir um futuro com as crianças. A escola eleva-se sobre a experiência e a interação. A reflexão abrange todas as formas de julgamento e prepara todas as dimensóes da ação, pois o professor deve mostrar as coisas e orientar para elas. É aí que suas competências de ensino cessam. No fim do período de orientação, educador e educando podem consultar-se no mesmo horizonte de olhar. O educador já não é mais seu professor. No fim do ensino, não é mais o professor. No fim do governo, deixa de ser o professor. Isso faz parte da concepção de formação no ócio, da transição do sujeito para a vida. É esse o fim da educação. Essa transição para o fim do ensino não começa apenas aos 18 anos, 
mas muito cedo: do governo para o autogoverno, do ensino para o auto-ensino, do aconselhamento para o auto-aconselhamento.

Odair Neitzel: O senhor ocupou-se intensivamente em pensar e pesquisar pedagogia. Como vê o desenvolvimento da pedagogia desde a época dos prolegômenos, no fim dos anos 60 do século XX? Como é possível avaliar o estado atual da pedagogia como uma ciência?

Dietrich Benner: Herbart já exigiu que a pedagogia constituísse um campo próprio de pesquisa. Kant exigiu que a pedagogia fosse livre da ideia de justificação (Justiz loswerden). Deve ser um julgamento pedagógico e desenvolver-se na escola experimental. Em seguida, encontrar a transposição para a escola em geral. Fundar escolas experimentais era comum. Salzmann fundou algumas, os discípulos de Fichte foram a Pestalozzi, na Suíça, para fundar escolas. As escolas reformadas foram fundadas renovadamente. Na Alemanha, foram fundadas muitas escolas reformadoras e eu mesmo, com Jörg Ramseger, fundei uma pequena escola em Münster. Mas sobre como pesquisar nela permanece uma questáo difícil e aberta. Nem todo o movimento pedagógico no início do século XX foi suficiente para desenvolver uma concepção de pesquisa pedagógica convincente.

Essa era a pretensão nos anos 1960 e 70, mas o problema era que não possuíamos um método pelo qual isso pudesse ser realizado. Todas as escolas de pesquisa de Helmut Fendt provaram que o desenvolvimento de educandos com dificuldades não ocorria em todas as escolas, principalmente em escolas secundárias tradicionais.

O que mudou na pesquisa? Eu acho que algumas coisas mudaram. Há uma pesquisa biográfica no sistema educacional que descreve e mostra de um prisma muito diferente a função da educação nos diversos estágios de formação dos sujeitos. Mostra que a escola ensina coisas que você só aprende lá. Mostra, porém, que as crianças obtêm a força para a aprendizagem principalmente de suas famílias e do meio social. Assim, a pesquisa biográfica explora estágios formativos encontrados de modos muito diversos nos variados espaços, mas é possível apreender em pesquisas biográficas como os programas de educação podem ser otimizados. Então, temos uma segunda grande mudança. Penso que é uma pesquisa educacional empírica como vem se desenvolvendo a partir dos anos 2000. A pesquisa educacional empírica pode desenvolver pesquisa para domínios específicos e para a aprendizagem escolar. Domínios específicos porque, se retirarmos a estrutura especializada da escola, nenhum ensino é possível. Assim já é em Aristóteles. Para ensinar, é necessária uma estrutura disciplinar. Se essa estrutura disciplinar for negada, por meio de um ensino geral relativo ou um modelo de meramente "aprender para viver", entáo fica indefinido o que entendemos por ensino.

A pesquisa educacional empírica desenvolveu modelos de avaliação de competências de domínio específico para leitura, matemática, geometria, língua estrangeira. Há testes de comparação internacional, mas ainda com déficits teó- 
ricos educacionais, como o teste no campo das linguagens, no qual percebo a ausência da retórica. A competência retórica - capacidade de articular um conjunto de pensamento de tal forma que o destinatário seja levado a tomar parte do pensamento, do julgamento e ensino — não é explorada.

Minha tese é que podemos desenvolver a pesquisa empírica educacional para uma investigação sofisticada de formação e competências educacionais. É necessário, então, quebrar o ensino em blocos. Faz-se preciso perguntar o modo e a forma de ensino a exigir-se e quais as competências para quais crianças.

E isso se pode medir. Pode-se medir uma competência anterior a uma de fase de ensino mais longa. Em seguida, podem-se experimentar diferentes formas de ensino e, por fim, medir o progresso dessas competências. Então teremos finalmente alcançado na ciência da educação o que Herbart e Kant exigiram: que a educação se torne um círculo próprio e uma pesquisa própria, na qual sejam realizados testes, dos quais surja a própria força de julgamento, sendo testados em escolas experimentais e finalizados nas escolas em geral. Vejo nossa disciplina no caminho para a pesquisa da educação e da formação. Trabalho isso atualmente na educação básica nas áreas religiosa, ética e moral. Essa é uma visão completamente diferente da pesquisa educacional empírica em seus protagonismos.

Em meu último estudo, distingo três formatos de atividades de investigação, nomeadamente: competência, didática e avaliação. Uma atividade de investigaçáo da competência apresenta o nível de correspondência de um educando no julgamento dos conhecimentos básicos e na participação nas reflexôes. Em uma atividade didática, investiga-se a estrutura de desenvolvimento de uma proposta ao longo de um período de tempo. E uma atividade de investigação avaliativa é uma atividade conclusiva, um ensaio e exame do trabalho. A investigação desenvolve um trabalho com base em um problema. Em uma investigação, soluciona-se um problema, mas sempre se trabalha com um problema.

Em síntese, distingui três causalidades nos processos educacionais e de formação. Causalidade educacional é o que o professor faz. Ele mostra algo, pergunta, organiza um curso. Nesse sentido, Klaus Prange (2013) escreveu uma pedagogia operativa do mostrar. Eu mostro, pergunto e respondo o que estiver relacionado. Assim, uma causalidade educacional é uma causalidade que se delineia pelo professor. Em segundo lugar, vem a causalidade formativa. Ocupa-se com a questão de como o aluno aprende uma coisa. $\mathrm{Na}$ ação pedagógica da disciplina formativa ou do aconselhamento ele aprende com um problema. Não com o professor. Não se aprende com o professor de matemática, religião e física. Aprende-se na revelação da coisa matemática, religiosa e física, na causalidade educacional em que opera o educador. A causalidade formativa é uma atividade em que um estudante se aprofunda, como pensava Herbart. O professor insiste para que o educando se aprofunde. $\mathrm{O}$ aluno aprofunda-se na coisa. 
Então há a terceira causalidade, da interação entre educação e formação, que é uma causalidade metodológica. Ela leva à formação de pensamento, questionamentos e julgamentos. Se existe essa competência metódica, então o professor não é mais necessário. A causalidade metódica traz o fim da educação. É assim em todas as áreas de saber. $\mathrm{O}$ professor ensina a matemática para que o aluno comece a reconhecer questóes e problemas matemáticos. Em seguida, o aluno interage com assuntos matemáticos. Quando isso é alcançado, o ensino chegou a certa conclusão.

E agora eu imagino que estamos realizando uma pesquisa em sala de aula examinando as três causalidades em seu contexto. Como as causalidades educativas atuam sobre as causalidades formativas e como por meio delas ocorrem as causalidades metodológicas? E depois as investigamos. Assim, uma pesquisa docente que argumenta com essas três causalidades seria um passo adiantado na pesquisa didática, como se viu na pesquisa de educação empírica no desenvolvimento do teste que pode ser alcançado pela otimização teórico-educacional.

Odair Neitzel: A minha impressão é que a Pedagogia Geral é a obra em que Herbart delineia seu projeto pedagógico. A Pedagogia Geral possui uma estrutura em três partes: o governo das crianças, o ensino educativo e a disciplina formativa. Esses conceitos ainda desempenham papel importante na educação atual (teórica e prática)?

Dietrich Benner: $O$ governo como a primeira forma de ação pedagógica é, no caso de Herbart, a forma que antecede a educação em geral. O governo ainda não é educação. É uma preparação para que seja possível educar. Na sala de aula, o professor precisa estabelecer um ambiente de aprendizado antes de iniciar o ensino. A arte do governo permite reconhecer em uma aula uma reuniáo para o ócio. Esse governo é necessário, especialmente na sociedade moderna. Devo ser capaz de persuadir as crianças a deslocar suas vontades para uma situação de ócio. Caso contrário, não posso começar com a educação. Em segundo lugar, sobre a ação pedagógica do ensino educativo, eu me envolvo com a experiência e as relaçóes das crianças, mas não para viver com elas. Envolvo-me especialmente para ampliar essa experiência e esses convívios. Essa é a questão da educação em Paulo Freire. Eu não apenas vivo com você porque eu não estou socializado nesse lugar, mas porque eu deixo esse espaço em que estou socializado por causa da ação do ensino. Sobre a disciplina formativa, Herbart diz: a disciplina vem de puxar (ziehen), não de castigar. Puxar, orientar, trazer para o caminho. Quando não sabemos disso, interpretamos erroneamente o termo disciplina. Portanto, o conceito de governo é perigoso, porque o governo é uma determinação externa. Mas o governo de Herbart está voltado para o autogoverno. É negativo: apenas impede a ação. O ensino leva a mudanças na ordem do conhecimento e da simpatia. Alarga para muitos horizontes, mas isso não determina o que a criança faz e quer.

Segue-se o aconselhamento (beratung). A disciplina como aconselhamento é sempre um suporte. Isso é muito moderno. Phillippe Ariès (1981) mos- 
trou, em sua História Social da Criança e da Família, que no século XX, no último terço, em todo mundo, a educação converteu-se de uma educação de governo para uma educação de suporte. Isso é Herbart. A educação deve ser eficaz como uma educação de apoio. O mesmo vale para Schleiermacher. Essa tríade de governo, ensino e disciplina é universal. Nós precisamos educar na educação pré-escolar, na pedagogia da família, na pedagogia escolar, na pedagogia social, em todos os lugares.

Finalizei, recentemente, um curso de formação de professores na China. Eles me perguntaram: onde podemos ensinar no jardim de infância? Respondi: quando vocês cantam uma música com as crianças, estão ensinando algo conforme Herbart. Diga às crianças onde a música surgiu, em que contexto, em que diferentes situações foi cantada e, então, ensaiem e pratiquem a música. Isso é um ensino educativo. Com isso, as crianças apresentam experiências e açóes que são aspectos relacionados com a música. Façam da mesma forma jogando um jogo ou quando estão brincando com as crianças. Conte a história desse jogo, o que significa em outros tempos e o que não tem no presente e, pela história, pode levar a ele. Quando aconselham para que uma criança resolva um conflito, também a ensine a interpretar as regras propostas. Então ela tem um ensino sobre as regras.

Na minha própria Pedagogia Geral (BENNER, 2012), existe um capítulo em torno da dimensão da interação na prática pedagógica - e aí tem força como governo, ensino e aconselhamento. Essa é a Pedagogia Geral de Herbart um pouco modernizada. Mas também tenho outras partes: a noção de práxis, que coloca educação entre religião, ética, política, trabalho e arte; um conceito de práxis que se refere à corporeidade, liberdade, historicidade, linguagem; princípios, e aqui vem o princípio herbartiano de educabilidade, o importante princípio da demanda por ocupar-se consigo mesmo, de transformaçáo pedagógica e de náo hierarquização. Tudo o que tem a ver com a pedagogia não precisa estar em uma relação hierárquica. O resultado é táo importante quanto o processo. Quando faço formação moral, não posso dizer que a ética é mais importante do que a educação. Não! Ambos estão em uma relação não hierárquica. Não posso fazer isso pedagogicamente. A pedagogia não pode ser a ponta, mas ela também não é a serva.

Odair Neitzel: Entre os muitos conceitos e tópicos abordados por Herbart na Pedagogia Geral, considero especialmente importantes os conceitos de "interesse múltiplo" e "fortaleza do caráter moral". O que nos poderia dizer sobre esses conceitos?

Dietrich Benner: Se você toma a publicação da Pedagogia Geral de Herbart organizada por Walter Asmus, que tem muitos méritos, encontra, porém, uma falha no capítulo que trata da força do caráter moral, um erro terrível no terceiro livro. Há uma passagem na segunda página em que Herbart diz:

Em caso de oposição, qual das duas vontades determina o carácter? - É evidente que aquilo que reunido o teria fortalecido, agora apenas o desequilibra e desconcerta. E que as melho- 
res exigências feitas a nós próprios (se, ao menos, impedirem cair-se naquilo que é decididamente mau) podem, quando muito, conter um benéfico caráter estabelecido (HERBART, 1965, p. 103-104).

É elementar, na formação do caráter, que a criança possua um caráter e que ela já fundamente por si mesma. Auto-avaliação! O aconselhamento provoca a auto-avaliação da própria vontade, que pode argumentar ou discordar da auto-avaliação. Há também uma terceira situação: quando alguns argumentos parcialmente concordam ou negam e a vontade precisa ser modificada.

Então, vem a pergunta: como lidar com o consentimento ou com o conflito? Herbart diz: é muito claro que o que fora reunido é o que pretendia definir o caráter e agora está sendo criticado. O caráter motiva, integra a melhoria, desenvolve um si mesmo. Só reconhece a luta interna para desenvolver o caráter. Na formação do caráter, você deve garantir que a criança identifique o que é mau. Mas é preciso deixar um espaço para que ela possa experimentar, testar ações e relações que permitam reconhecer isso em suas ações. Você deve evitar que ela escorregue para o que é decididamente ruim, e isso se faz também na ação negativa do governo. Mas é sempre preciso proporcionar e convidar a criança para uma atmosfera curativa do caráter indeterminado. Herbart fala de um saudável caráter indeterminado (heilsame Charakterlosigkeit), diferentemente de Asmus, que trata de um saudável caráter determinado (heilsame Charakterfestigkeit). Asmus não tinha necessidade de mudar indeterminado por determinado. Ele considerou que, por um caso flagrante, Herbart substituíra uma palavra pelo seu contrário.

A formação do caráter de uma criança moderna deve sofrer impedimentos para desenvolver um caráter sólido muito cedo. Este é o programa de Herbart: a pessoa deve interessar-se por liberdade, benevolência, justiça, equidade. Mas no começo o caráter moral ainda não pode ser firme. O caráter ético deve julgar, mas inicialmente não como ação final. Uma criança [um adolescente] de 14 anos com o caráter moral solidificado como o de um homem ou mulher adulta seria algo terrível. O caráter moral deve ser mantido educável, e não tomar determinada forma. E essa é a relação entre formação do interesse múltiplo e do caráter. O caráter precisa também ser múltiplo.

Herbart defende que a criança deve ser preservada saudável e indeterminada em seu caráter. É terrível que em uma família cujo pai é médico as crianças sejam educadas de modo que aos 9 anos já sejam médicas. Não! Elas devem ter muitos interesses, muitos sentimentos humanos, conhecer muitas formas de sociabilidade. Tudo o que Rousseau afirma no Emilio ou Da Educação (2014), Herbart propóe nesse espaço. Emílio não deve possuir caráter unilateral. Ele deve ser compreendido na educabilidade. Com isso, penso que a própria teoria herbar- 
tiana da formação do caráter ético, a teoria herbartiana do ensino e da formaçáo do interesse múltiplo e a teoria não formadora herbartiana do governo das crianças são de significado muito atual.

Odair Neitzel: Finalmente, o que o senhor recomendaria hoje para continuar desenvolvendo a pedagogia e a formação dos pedagogos?

Dietrich Benner: Eu gostaria de responder a isso visualizando a formação dos pedagogos. Sempre no primeiro semestre de aula, eu buscava inseri-los na pedagogia. Eu buscava refletir sobre a sua própria experiência de formação, aproximando-os com a Pedagogia Geral de Herbart, com a minha própria Pedagogia Geral, ou, ainda, uma mistura delas ou mesmo uma mistura com outras pedagogias. Sempre partia da afirmação de que, até aquele momento, eles foram educados. Agora deveriam preparar-se para educar os outros. Deveriam começar a dirigir-se reflexivamente para sua própria formaçáo. E isso é uma preparação extraformativa (Ausbildung)! Tomar distância do seu processo formativo para que se possa aprender o que náo foi experimentado em sua formação. $\mathrm{Ou}$ seja, o lado do educador em todo o seu percurso formativo e de socializaçáo. Esse é o início do preparo de educadores para mim. Não é aprender a criticar os pais ou os professores. Não! Para tanto, é preciso analisar teórica e empiricamente a situação educacional. Ser capaz de analisar situaçóes pedagógicas significa: onde está a atividade formativa? Onde está a atividade educacional? Onde está a atividade interativa? Onde é mostrado algo sem a compreensão do aluno? Onde é perguntado e previsto sem que a questão seja esclarecida? Onde os alunos responderam a algo completamente diferente do que fora perguntado pelo professor? Como o educador resolve essa desarmonia entre perguntas e respostas em vez de responder a elas? Então, esse é o espaço onde analisaremos situaçóes educacionais. E então vem a dimensão em que você pergunta praticamente: por que e como você planeja suas aulas? Como você planeja suas liçóes? Por que você agiu assim em um lugar e diferente no outro? Aqui há a necessidade de uma hermenêutica da ação. E, em seguida, uma pesquisa entre o projeto, a realização e a pesquisa de impacto.

Em primeiro lugar, autorreflexão. Tomar distância da própria educação e preparar-se para uma profissão pedagógica. Em segundo, análise. Como posso analisar situações educacionais e descrevê-las pedagogicamente? Como posso projetar, assessorar, governar, ensinar açóes pedagógicas? Como posso relacionar projeto, realizaçáo e efeitos? Imagino isso como um treinamento educacional, como uma introdução à profissão e teorização da pesquisa.

Berlim, 14 de novembro de 2017. 


\section{Referências}

ANHALT, Elmar. Bildsamkeit und Selbstorganisation: Johann Friedrich Herbart Konzept der Bildsamkeit als Grundlage für eine pädagogische Theorie der Selbstorganization organismischer Aktivität. Weinheim: Beltz, Deutscher Studien Verlag, 1999.

ARENDT, Hannah. A Crise na Educação. In: ARENDT, Hannah. Entre o passado e o futuro. Tradução de Mauro W. Barbosa de Almeida. São Paulo: Perspectiva, 2013. p. 221-246.

ARIÈS, Phillippe. História Social da Criança e da Família. São Paulo: LTC, 1981.

BENNER, Dietrich. Allgemeiner Pädagogik: ein systematische-problemgeschichtliche Einführung in der Grundstruktur pädagogischen Denkes und Hadels. Weinheim und Basel: Juventa Verlag, 2012.

BENNER, Dietrich. Bildung-Moral-Demokratie: Theorien und Konzepte moralische Erziehung und Bildung und ihre Beziehung zu Ethik und Politik. München: Ferdinand Schöningh, 2015.

BENNER, Dietrich. Die Pädagogik Herbarts: Eine problemgeschichtliche Einführung in die Systematik neuzeitlicher Pädagogik. Weinheim: Juventa, 1993.

BENNER, Dietrich. Hauptströmungen der Erziehungswissenschaft. München/ Weinheim/Basel: Deutscher Studienverlag, 2001. 4 v.

BENNER, Dietrich. Schule und Bildung - Widerspruch oder Entsprechung? In: MERTENS, GERHARD et al. (orgs.). Schule: Handbuch der Erziehungwissenschaft. Paderborn München/Wien/Zürich: Ferdinand Schöningh, 2011. p. 7-28.

BENNER, Dietrich; BRÜGGEN, Friedhelm. Die Bildung pädagogischer Urteils - und Handlungskompetenz als Aufgabe des Pädagogikunterrichts im öffentlichen Schulsystem. In: BOLLE, Rainer; SCHÜTZENMEISTER, Jörg (Orgs.). Die pädagogische Perspektive. Hohengehren: Schneider Verlag, 2014.

BENNER, Dietrich; SCHMIED-KOWARZIK, Wolfdietrich. Prolegomena zur Grundlegung der Pädagogik: Die Pädagogik der frühen Fichteaner und Hönigswalds. Wuppertal/Ratingen/Düsseldorf: A. Henn Verlag, 1969. v. 2.

BENNER, Dietrich; SCHMIED-KOWARZIK, Wolfdietrich. Prolegomena zur Grundlegung der Pädagogik: Herbarts praktische Philosophie und Pädagogik. Ratinger bei Düsseldorf: A. Henn Verlag, 1967. v. I.

DEWEY, John. Democracia e Educação: introdução à filosofia da educação. Tradução de Godofredo Rangel e Anísio Teixeira. São Paulo: Companhia Editora Nacional, 1979.

FOUCAULT, Michel. A Hermenêutica do Sujeito. Tradução de Márcio Alves da Fonseca e Salma Annus Muchail. São Paulo: WMF Martins Fontes, 2010.

HERBART, Johann Friedrich. Allgemeiner Pädagogik aus der Zweck der Erziehung Abgeleitet. In: KEHRBACH, Karl; FLÜGE, Otto; FRITZSCH, Theodor (Orgs.). Johann Friedrich Herbart's sämtliche Werke in chronologische Reihenfolge. Langensalza: Hermann Beyer \& Söhne, 1887. v 2. p. 1-136. 
HERBART, Johann Friedrich. Allgemeiner Pädagogik aus dem Zweck der Erziehung abgeleitet. In: ASMUS, Walter (org.). Johann Friedrich Herbart Pedagogische Grundschriften. Düsseldorf und München: Verlag Helmut Küper Vormals Georg Bondi, 1965. v. 2. p. 9-158.

HERBART, Johann Friedrich. Zwei Vorlesungen über Pädagogik [1802]. In: KEHRBACH, Karl; FLÜGE, Otto; FRITZSCH, Theodor (Orgs.). Johann Friedrich Herbart's sämtliche Werke in chronologische Reihenfolge. Langensalza: Hermann Beyer \& Söhne, 1887b. v 1. p. 279-290.

HERBART, Johann Friedrich. Allgemeiner Pädagogik aus der Zweck der Erziehung Abgeleitet. In: KEHRBACH, Karl; FLÜGE, Otto; FRITZSCH, Theodor (Orgs.). Johann Friedrich Herbart's sämtliche Werke in chronologische Reihenfolge. Langensalza: Hermann Beyer \& Söhne, 1887c. v 2. p. 1-136.

HERBART, Johann Friedrich. Allgemeiner Praktische Philosophie. In: KEHRBACH, Karl; FLÜGE, Otto; FRITZSCH, Theodor (Orgs.). Johann Friedrich Herbart's sämtliche Werke in chronologische Reihenfolge. Langensalza: Hermann Beyer \& Söhne, 1887. v 2. p. 329-458.

NEITZEL, Odair. A pedagogia como autogoverno em Johann Friedrich Herbart. Doutorado em Educação - UPF, Passo Fundo, 2018. 133 p.

PRANGE, Klaus. Zeigen - Lernen - Erziehen. Jena: Edition Paideia, 2013. v. 13. (Pädagogische Reform).

ROUSSEAU, Jean-Jacques. Emílio ou Da educação. Tradução Roberto Leal Ferreira. São Paulo: Martins Fontes, 2014. (Paideia).

SCHWENK, Bernhard. Das Herbartverständnis der Herbartianer. Göttinger ed. Weinheim: Beltz Juventa, 1963.

WALZER, Michael. As esferas da justiça: uma defesa do pluralismo e da igualdade. Tradução de Jussara Simóes. São Paulo: Martins Fontes, 2003.

\section{SOBRE O AUTOR}

Odair Neitzel é Doutor em Educação; Docente no magistério superior na Universidade Federal da Fronteira Sul - Campus Chapecó.

Recebido em 10 de julho de 2018.

Aceito em 09 de abril de 2019.

(C) 2019 Centro de Estudos Educação e Sociedade - CEDES Este é um artigo de acesso aberto distribuído nos termos de licença Creative Commons. 